\title{
Guest editorial: Heritage interpretation, conflict and reconciliation in East Asia
}

Memory politics has been and is increasingly a popular topic in the fields of heritage, memory and history studies, including the links between memory politics and trauma, and the implication of commemoration in political power and identity-making (Macdonald, 2013). Seminal publications in this field are now about 20 or more years old (for example, Nora, 1989; Huyssen, 1995; Edkins and Jenny, 2003; Pitcher, 2006; Bell, 2006). Various forms of placeholders of memory have been examined, such as heritage sites, museums and memorials. In recent years, scholarship has maintained a steady output, including Berger and Tekin (2018) on the contested premises underlying the European Union's ambition to develop a common historical narrative of Europe, Hubbell et al. (2020) on places of traumatic memories and the special issue of European Politics and Society (2020) on the politics of memory and oblivion. Topics have expanded from sites to rituals and commemoration practices that are associated with wars, genocides, terrorism and revolutions.

Scholarly debates have often focused on the roles of social and political elites in constructing national remembrance. These discussions engage with how various forms of memory are used, interpreted and revised by political agents to serve present interests and ideologies (Kaasik-Krogerus et al., 2020). These issues can trace back to Pierre Nora's (1989) classical work on les lieux de mémoire (sites of memory), who argued that the promotion of national history and sites of memory facilitated the development of a collective national memory that homogenised local memories in France. To broaden the current critical debate, this issue adopts an extended and more nuanced understanding of memory politics that includes grassroots involvement in heritage contestation and the international dynamics resulting from the extra-territorial significance of much heritage. Here, the discussion of politics of memory and history does not simply refer to the representation of national and collective memory but also focuses on their performative role in shaping political reality (Meyer, 2008).

In particular, this special issue shifts the discourse by focussing on heritage interpretation, that is the attribution of meaning and significance to historical places, documents and other material artefacts and intangible skills, representations and practices. The papers in this issue analyse the impact of interpretation of heritage and sites of memory on nation-building and the shaping of international relations. They also demonstrate the strategic extraterritorial and geopolitical roles that heritage interpretation can play. Often these interpretations have been inadequate, incomplete and ideologically framed and caused difficulties when attempts were made to have them recognised by global heritage agencies, such as UNESCO.

Indeed, such interpretations have perpetuated tensions between states in post-conflict contexts. In this special issue, we suggest principles that might be adopted by policymakers seeking to use heritage and sites of memory to achieve more complete reconciliation between states recently engaged in international conflicts. Several recent studies have begun this work, raising debates about whether and how heritage could be used positively to move communities forward and promote change (for example, Sørensen et al., 2019; Scham and Yahya, 2003). This includes acknowledging and contending with racial differences, enabling

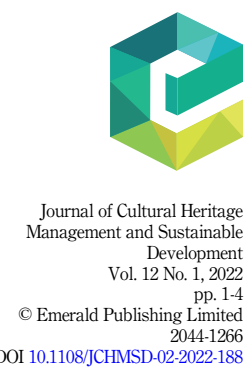


JCHMSD 12,1 the empowerment of minority groups, providing self-determination and self-worth in community building and working towards a shared heritage or, if not shared, at least developing an appreciation of each other's heritage interpretations (Zhu, 2021). It may also entail the repatriation of objects and lands. It raises, too, the role that heritage and sites of memory can have in international dialogue concerning human rights, peacebuilding, war commemoration and victim diplomacy (Larsen and Logan, 2018).

The special issue also shifts the geographical focus. Despite emerging research about Asia, the main discussion on the links between history, politics, heritage and memory has been based on research concerning Western societies, particularly examining the 20th century "memory boom" after the two world wars and the Holocaust. We wish to provide an alternative, Asian empirical lens in this special issue. It is always wise to tread carefully in representing "Asian" heritage given Asia's great diversity, and in this special issue, the papers deal only with East Asia, with case studies from China, Japan, South Korea and Taiwan.

Using examples of heritage interpretation in East Asia, however, and especially focussing on heritage places but also referring to intangible and documentary heritage, William Logan's paper shows how governments use heritage in their efforts to create and maintain community cohesion around a set of core values even though this often means the imposition of the dominant group's interpretation at the expense of minority cultures within the state. Similarly, heritage interpretation may serve to enable the identification of cultural commonalities between states and therefore strengthen international relations, but it may highlight differences between states and provide a rationale for various forms of hard and soft power conflict. Logan suggests how the organisations and agencies charged with heritage protection might modify their interpretation policies and procedures to help alleviate the situation. To this end, he discusses the interpretation process, distinguishing it from the presentation or communication of interpretations.

Edward Boyle's paper elaborates on the troublesome World Heritage inscription of the "Sites of Japan's Meiji Industrial Revolution" mentioned by Logan. Examining the protests that erupted in June 2020 following the opening of the Industrial Heritage Information Centre in Tokyo, Boyle argues that the disputation reflects how the serial sites have been collectivised through UNESCO's recognition into a single "border of memory" between Japan and Korea, one which the Information Centre has succeeded in materialising and reproducing within Japan's national capital. The centre is a re-purposed administrative office building in the Shinjuku suburbs. Using the term "border of memory," Boyle demonstrates the de-territorialising imperatives of national memory. It further shows how disagreements over micro-historical processes occurring at particular material sites of heritage are refracted through contemporary contestation over the respective national histories of Japan and South Korea.

Yujie Zhu explores the political role heritage interpretation plays at post-conflict heritage sites and proposes four goals that heritage interpretation can seek to achieve: (1) knowledge and fact sharing; (2) understanding and recognition; (3) imagination and reflection; (4) peacebuilding and reconciliation. Using the example of the Memorial of the Nanjing Massacre, one of the most important sites of memory in China, he raises important questions by asking, "Does heritage interpretation only serve the purpose of nationalism, or can it facilitate transnational dialogue, reflexivity, and recognition?". Zhu examines the processes involved in interpreting and presenting the traumatic past to both domestic and international audiences. He argues that interpretations in the museum still serve as an authorised educational tool aligned with contemporary social and political national agendas. To this end, Zhu suggests that a collaborative framework of heritage interpretation is required in order to archive better outcome of dialogue and peacebuilding in the region. 
The extent to which the state influences heritage interpretation is also the focus of Fengqi Qian's paper. Using the current development in China of a World Heritage nomination for the "Maritime Silk Road", she examines the guiding ideology of the nomination and the Chinese interpretation of the ancient Maritime Silk Road underlying it, particularly in the context of China's contemporary ambitions in the Asia Pacific region. This raises the issue of how memory and heritage interpretation connect with the nation-state and transnationality. Qian argues that under the impact of globalisation, memories transcend national boundaries to become transnational and that this presents a new and challenging framework for memory study at the centre of which are notions of constructionism and instrumentalism. The case study leads to the conclusion that the Chinese state continues to play a critical role in memory making, narrative formation and heritage interpretation and that these serve China's ambitions in the region, in particular its Belt and Road Initiative.

Li Narangoa turns our attention to the very romantic image that the Japanese have of the Mongolian steppe. She explains how this romantic image comes not only from visions of a land of endless green grassland that is so very different from the ecology of Japan but also the historical memories and myths associated with the Mongol Empire and its invasions of Japan in the 13th century. These mingled memories and myths have been told and retold many times over the centuries. They were particularly important in the creation of a unified Japanese identity during Japan's efforts to build a modern nation-state. Japan's links (real or imagined) with the Mongol empire, the largest land empire in world history, were used to boost its self-image as a sovereign and strong empire that was as powerful as those established in the West, if not more. At the same time, memories of the Mongol invasions were useful for promoting national unity and a new self-image of a god-protected land. Narangoa also demonstrates how most of these memories and myths about the Mongol Empire have very strong connections with particular local histories in Japan; indeed, in many cases, the utilisation of them for political purposes began as local initiatives. She argues, however, that these local interpretations were taken up by Japanese policymakers and nationalists and generalised to form the history and identity of Japan as a whole.

The reshaping of a state's identity by incorporating previously overlooked communities and their history and heritage is the subject of Shu-Mei Huang's paper on Taiwan. She outlines how over the past two decades, Taiwan has tried to mobilise its prehistoric Austronesian linguistic heritage and indigenous cultural memories to reposition itself in the Asia-Pacific. This has involved cross-border exchange and partnership based on the interconnectivity across the Pacific in line with the ancient legend of Maori people having ancestral roots in eastern Taiwan. Increasingly, the past connection is contributing to building up new cultural circuits based on shared indigenous heritage, with the nation-state moving towards institutionalising the Austronesian Forum and the civic groups building up indigenous exchange across borders. However, Taiwan has not always had an easy relationship with its indigenous people. The indigenous people became imperial subjects of the Japanese empire before the Second World War and have lived, as Huang argues, under the quasi-colonial rule of the settler state in Taiwan after the war ended. Therefore, Huang's paper sheds light on the complex and sometimes inconvenient relationship between interpreting history, heritage making and nation-building. It demonstrates, too, the strategic extraterritorial and geopolitical roles that cultural heritage can play. Huang concludes that wider public recognition of the colonial character of the contemporary Taiwanese state and the incorporation of indigenous heritage are necessary if Taiwan is to achieve a multilateral, multi-temporal reconciliation with its past(s).

As editors, we hope these studies can provide a different lens with which to advance knowledge on the politics of memory and heritage interpretation. This is not to say that the challenges and trends identified in East Asia are not found elsewhere, as William Logan's paper explains; indeed, they apply to contexts across the world where heritage 
JCHMSD interpretations have been implicated in undermining cultural rights and fomenting tensions 12,1 between states and between peoples within states. We hope, too, that this collection of papers will provide a better picture of how heritage management approaches and mechanisms might foster dialogue and mutual understanding within and beyond nation states.

Yujie Zhu Centre for Heritage and Museum Studies, Australian National University, Canberra, Australia, and

William Logan Arts and Education, Deakin University, Melbourne, Australia

\section{References}

Bell, D. (Ed.) (2006), Memory, Trauma and World Politics: Reflections on the Relationship between Past and Present, Springer, New York.

Berger, S. and Tekin, C. (Eds) (2018), History and Belonging: Representations of the Past in Contemporary European Politics, Vol. 33, Berghahn Books.

Edkins, J. and Jenny, E. (2003), Trauma and the Memory of Politics, Cambridge University Press, Cambridge.

Hubbell, A., Akagawa, N., Rojas-Lizana, S. and Pohlman, A. (Eds) (2020), Places of Traumatic Memories: A Global Context, Palgrave Macmillan, London.

Huyssen, A. (1995), Twilight Memories: Marking Time in a Culture of Amnesia, Routledge.

Kaasik-Krogerus, et al. (2020), "Special issue: contemporary uses of the past. Politics of memory and oblivion”, European Politics and Society, Vol. 21 No. 3.

Larsen, P.B. and Logan, W. (Eds) (2018), World Heritage and Sustainable Development: New Directions in World Heritage Management, Routledge, London.

Macdonald, S. (2013), Memory lands: Heritage and Identity in Europe Today, Routledge, London; New York.

Meyer, E. (2008), "Memory and politics", in Erll, A. and Nünning, A. (Eds), Cultural Memory Studies: an International and Interdisciplinary Handbook, De Gruyter, Berlin, pp. 173-180.

Pitcher, M.A. (2006), "Forgetting from above and memory from below: strategies of legitimation and struggle in postsocialist Mozambique", Africa, Vol. 76 Special Issue 1, pp. 88-112.

Scham, S.A. and Yahya, A. (2003), "Heritage and reconciliation", Journal of Social Archaeology, Vol. 3 No. 3, pp. 399-416.

Sørensen, M.L.S., Viejo-Rose, D. and Filippucci, P. (2019), "Memorials and memorialisation: history, forms, and affects", in Sørensen, M.L.S., Viejo-Rose, D. and Filippucci, P. (Eds), Memorials in the Aftermath of Armed Conflict: from History to Heritage, Palgrave Macmillan, Cham, pp. 1-32.

Zhu, Y. (2021), Heritage Tourism: from Problems to Possibilities, Cambridge University Press, Cambridge. 